УДК 130.1

DOI: $10.18101 / 1994-0866-2019-2-3-11$

\title{
ПРОБЛЕМА СУЩНОСТИ ДУШИ И ЕЕ БЕССМЕРТИЯ В РУССКОЙ ДУХОВНО-АКАДЕМИЧЕСКОЙ ФИЛОСОФИИ ХІХ В.
}

\section{(C) Цвык Ирина Вячеславовна}

доктор философских наук, профессор кафедры философии,

Московский авиационный институт

(национальный исследовательский университет),

Россия, 125993, г. Москва, Волоколамское шоссе, 4

Российский университет дружбы народов

Россия, 117198, г. Москва, ул. Миклухо-Маклая, 6

E-mail: tsvykirina@mail.ru

Статья посвящена анализу учения о душе, ее происхождении и бессмертии, сформулированному в рамках русской духовно-академической философии XIX в. Рассматриваются логико-рационалистическое и этикоантропологическое направления в духовно-академических интерпретациях проблемы сущности и происхождения души. Отмечается, что проблемы души и ее бессмертия в духовно-академической традиции обсуждались в русле двух разнонаправленных тенденций: в духе психологического идеализма, в большей степени свойственного Киевской и Казанской духовным академиям, и в соответствии с общими установками «верующего разума» Московской и Санкт-Петербургской академий. На основании анализа духовноакадемической аргументации положения о бессмертии души делается вывод о том, что строго логичного, рационального обоснования бессмертия души, как и бытия Бога, в духовно-академической философии не произошло. Пытаясь обосновать бессмертие души, представители духовно-академической мысли были вынуждены обратиться к богословской аргументации, чтобы не выйти за пределы православного учения. Тем не менее постановка вопроса о возможности философской интерпретации бессмертия души в рамках православной умозрительной, рациональной психологии, а также православная интерпретация осмысления этой проблемы западноевропейской философской мыслью свидетельствуют о том, что эти попытки академических профессоров не были абсолютно бесплодными в теоретическом отношении и сыграли свою роль в развитии гносеологической проблематики русской философии конца XIX - начала XX в.

Ключевые слова: духовно-академическая философия; душа; познание; религиозное сознание; бессмертие души; умозрительная психология; рациональное богопознание; П. С. Авсенев; Ф. А. Голубинский; В. Н. Карпов.

Для цитирования:

И. В. Цвык. Проблема сущности души и ее бессмертия в русской духовноакадемической традиции философии XIX в. // Вестник Бурятского государственного университета. Философия. 2019. Вып. 2. С. 3-11. 
Духовно-академическая философия в России XIX в. - совокупность идей, разработанных профессорами философии российских духовных академий. Она представляет собой синтез православного вероучения и западноевропейской философской методологии в создаваемых ее представителями системах философской интерпретации религиозного сознания. Одним из исходных принципов русской духовно-академической философии было стремление противостоять чуждым идеологическим влияниям. Становление духовно-академической философии в России XIX в. обусловлено потребностями развития философских учебных дисциплин в пореформенных духовных академиях - Московской, СанктПетербургской, Киевской и немного позже - Казанской. Философские труды профессоров этих академий создавались для чтения соответствующих учебных курсов и имели традиционную для того времени структуру: в них на профессиональном уровне анализировались онтологические, гносеологические, психологические и антропологические проблемы. В зависимости от исследовательских задач и от приоритета обсуждаемых проблем в духовно-академической философии можно выделить логико-рационалистическое и этико-антропологическое направления.

Этико-антропологическое направление в структуре духовно-академической философии XIX в. занимает свое особенное место. Несмотря на общие задачи создания систем рационалистического обоснования религиозного сознания, стоящие перед духовно-академическими мыслителями, особенно в первой половине XIX в., проблема человека, его сущности, природы, связи с Богом также требовала своего философского обоснования. В русле святоотеческой традиции духовно-академические авторы решали эту проблему, опираясь на принцип двойственности человеческой природы, обращаясь к его внутреннему опыту. Философско-антропологические изыскания духовно-академических авторов охватывали отношение человека к миру, его «действования» в нем, духовный опыт личности, задачи ее духовного самоусовершенствования. При этом вышедшая на первый план только в начале XX в. антропологическая проблематика успешно развивалась и в течение XIX в. Проблема сущности души, ее происхождения, обоснование ее бессмертия лежит в основе антропологический изысканий представителей духовно-академической философии XIX в.

Весьма показательным является тот факт, что эти проблемы рассматриваются духовно-академическими авторами наряду с проблемой рационалистического обоснования бытия Бога, причем, как правило, в рамках психологии, которая входила в круг духовно-академических философских дисциплин. Психология преподавалась в духовных академиях XIX в. наряду с метафизикой, логикой и другими философскими дисциплинами, в то же время в академических курсах психологии в основном делался акцент на опытную психологию как науку о душе, ее проявлениях и способностях. Часто сам курс психологии в академиях носил название «опытная психология» и включал в себя не онтологические, а гносеологические проблемы, связанные с познавательными функциями души. Проблематика бессмертия души также входила в психологические курсы, однако не являлась главным предметом обсуждения и рассматривалась в рамках умозрительной психологии.

Показательным в этом плане является психологический курс профессора Киевской духовной академии архимандрита Феофана (П. С. Авсенева), который 
И. В. Цвык. Проблема сущности души и ее бессмертия в русской духовно-академической традиции философии XIX в.

представлял собой систематическое изложение не только опытной, но и теоретической психологии: он достаточно подробно проанализировал происхождение, сущность и свойства души, в то же время основное внимание уделял как проявлениям «дневной жизни души», так и тем ее способностям, которые выходят за эти пределы - ясновидению, лунатизму, магнетизму [9, с. 211]. Ориентация Авсенева на необычные состояния души имела под собой определенные методологические основания: «Все силы, свойства и способности души, открывающиеся в необыкновенных состояниях, находятся постоянно в организме; но в необыкновенных состояниях души они действуют гораздо свободнее, а потому, естественно, и открываются яснее. Поэтому нисколько не удивительно, а, напротив, весьма естественно, что в рассмотрении этих состояний глубокомысленный психолог может найти, и действительно находит, гораздо разительнейшие проявления самостоятельности души, ее чисто духовного характера, бессмертного и богоподобного существа, чем какие сообщает обыкновенная, на одном только личном самосознании основанная психология... Исследование этих видоизменений и многоразличных состояний содержит в себе ключ к уразумению многих важнейших истин философии, нравственности и религии» [7, с. 78]. Н. К. Гаврюшин справедливо усматривает в данной программе Авсенева своего рода философский манифест, программу философской антропологии, основанной на изучении бессознательного и психических болезней [1, c. 24]. Хотя проблематика бессмертия души и ее божественного происхождения присутствовала в психологических размышлениях Авсенева, она не являлась основной - акцент делался на необычные, иррациональные состояния души, в то время как проблема бессмертия души и его философского обоснования рассматривалась в рамках не опытной, а умозрительной психологии.

Специфика духовно-академических интерпретаций бессмертия души заключалась в том, что, с одной стороны, сама постановка вопроса о душе, ее свойствах, способностях и проявлениях осуществлялась в русле антропологических интерпретаций, носящих в большей степени мистический, чем рациональный, оттенок (например, у архимандрита Феофана (Авсенева)), с другой — проблема бессмертия души решалась духовно-академическими авторами исходя из тех же методологических оснований, что и проблема бытия Бога, т. е. на основе логикорационалистического обоснования, и была включена в структуру духовноакадемической онтологии.

Так теоретическое обоснование божественной сущности души и ее бессмертия стало предметом умозрительной психологии, которая наряду с умозрительным богословием, ставящим своей целью обоснование бытия Бога, представляла собой онтологическую интерпретацию бессмертия души. Структура духовноакадемической онтологии, включающей в себя умозрительное богословие как учение о бесконечном духе, умозрительную психологию как учение о конечном духе - душе и умозрительную космологию как учение о конечном мире, четко прослеживается в трудах тех представителей духовно-академической мысли, которые в своих интерпретациях дошли до создания системы, например, у профессора Московской духовной академии В. Д. Кудрявцева-Платонова. Данная структура представлена и в лекциях по метафизике, читанных в середине XIX в. в Санкт-Петербургской духовной академии. 
Итак, идеальная сущность человеческой души, ее божественное происхождение, наконец, ее бессмертие интерпретировались в духовно-академической традиции в двух направлениях: во-первых, по «спиритуалистической» линии в русле «приспособления мистицизма к христианской умозрительной психологии», которое осуществляли архимандрит Феофан и его немногочисленные последователи, во-вторых, в рамках логико-рационалистического обоснования бессмертия души, главным образом, в рамках Московской и Санкт-Петербургской школ «верующего разума».

Феофан (Авсенев) понимал душу традиционно для православной мысли как некую часть в человеке, отличную и от низшего - своего тела и природы, и от высшего - Божественного. Интересно, что уже у Авсенева основной задачей психологии как науки о душе и ее проявлениях объявляется самопознание: «Наука, имеющая своим предметом изъяснить являющееся нам устройство и жизнь души из чистого ея существа, дабы привести человека в истинное самопознание, есть психология» [7, с. 2]. Но при этом к источникам психологии он относил как наблюдение (внутреннее и внешнее) и умозрение, которое «есть созерцание чистой мыслею того совершеннейшего, чуждого всех недостатков и ограничений, полного образца души», так и откровение, «получающееся» из Священного Писания; а самопознание трактовал исключительно как «отрешение» души от тела и углубление ее в саму себя, что возможно даже при психических болезнях.

К свойствам души Феофан относил: 1) стремление знать; 2) стремление наслаждаться; 3) стремление действовать, однако особое внимание уделял необычным состояниям души - лунатизму, магнетизму, ясновидению и т. д. Эта ориентация на иррациональные способности души, на исследование бессознательного была обусловлена стремлением раскрыть сущностную основу души. Вполне понятно, что при такой расстановке акцентов Авсенев делал упор на тесной связи человеческой души с Божественным бытием, полагая абсолютно бесспорной внушаемость души, ее тяготение к Бесконечному: «...полагаем за несомненное, что глубочайшее основание всех сил и действий души, то, в чем сосредоточиваются все лучшие ея стремления и способности, есть желание и способность души к восприятию Бесконечного» [7, с. 61]. Положение об устремленности человеческого духа к Бесконечному Авсенев обосновывал исходя из предпосылки, что Бог - творец души. При этом стремление духа к Бесконечному, по мнению Авсенева, доказывается как умственно - из цели сотворения (Бог, творя душу, поставил целью себя самого), так и опытно - из неудовлетворенности желаний души конечными предметами. Похожие рассуждения о субстанциальной недостаточности души и как следствие этого - ее стремлении к Абсолютному - можно встретить практически у всех представителей духовноакадемической мысли, в том числе и среди рационально-логической аргументации.

Несмотря на внешне традиционно-православную установку Авсенева на признание абсолютной связи человеческой души с Богом, увлечение исследованиями иррациональных состояний души и то значение, которое придавал им Авсенев, придали его рассуждениям оттенок мистицизма, достаточно сильный, чтобы исключить возможность использования его идей для решения общих задач духовно-академической философии XIX в. - рационального обоснования религиозного сознания. Однако линия психологического идеализма, продолженная в Казанской духовной академии В. А. Снегиревым и впоследствии В. И. Несмело- 
И. В. Цвык. Проблема сущности души и ее бессмертия в русской духовно-академической традиции философии XIX в.

вым, оказалась уже совершенно свободной от мистических настроений. Критика спиритуализма, предпринятая Снегиревым, его разработка теории бессознательного и основ православной антропологии, которую он понимал как науку о «непространственных» явлениях, присущих сознанию, позволяют сделать вывод о том, что в конце XIX в. духовно-академическая мысль уже преодолевала кризис логико-рационалистических построений и намечала положительную программу религиозно-антропологических интерпретаций [8, с. 232].

Однако в середине XIX в. аргументация в пользу невещественности и бессмертия души в трудах многих духовно-академических авторов была максимально приближена к рационально-логической, авторы стремились придать своим рассуждениям определенную «форму разумности». Так, профессор МДА Ф. А. Голубинский в своей «Умозрительной психологии» пытался представить логическое обоснование концепции «искры Божией», нетварного начала в человеческом существе. Признавая в соответствии с православной традицией человеческую душу трехчастной (как и у Авсенева), Голубинский мыслил ее, опять же в согласии с учением Церкви, сотворенной из ничего, но в то же время пытался обосновать идею наличия в духе человека, т. е. в высшей способности души, Божественной частицы. Таким образом, важное место в психологических построениях Голубинского занимало положение о врожденности душе человека идеи Божества.

Учение Голубинского о врожденности в человеческой душе идеи Бесконечного как основной предпосылке ее бессмертия представляет собой прямое следствие его попыток философской интерпретации традиционно-православного учения о душе. Идею ума о Бесконечном он полагал основным источником умозрительной психологии, которую также называл «рациональной психологией». Основной задачей этой «рациональной» науки о душе мыслитель считал теоретическое обоснование «сообразности человеческой души с Существом Бесконечным» и «познание лучшего в душе, богообразного» [2, с. 176].

В понимании Голубинским сущности души и в обосновании ее бессмертия не содержится ничего оригинального в сравнении с традиционно православной аргументацией: основными признаками души как богоподобной субстанции он полагал самостоятельность, простоту и невещественность (отдавая должное учению о душе как совершенной монаде Лейбница). Среди известных в истории философии доказательств бессмертия души Голубинский выделял платоновские, особенно «те, которые заимствованы из духовных свойств души», называя их «довольно основательными», и неоплатонические. Рассуждения Плотина о душе и уме Голубинский полагал достаточными и для современного обоснования бессмертия души. Таким образом, в основе доказательства бессмертия души Голубинским лежит аргументация Плотина, точнее тезис последнего о непосредственной очевидности бессмертия души в силу ее богоподобия и, постигаемого умом. Основным источником непосредственного восприятия богоподобия и, следовательно, бессмертия души Голубинский считал самосознание, полагая, что собственно сознание человека («conscientia sui impsius») как сознание «временного бытия души» предшествует раскрытию в человеке самосознания, обнимающего высшее, вечное бытие души. «Вечные» свойства души, по мнению Голубинского, можно отличить только «применяя действия души к идее Бесконечного»: таким образом, речь здесь идет о восприятии умом как высшей познавательной способностью человека идеи Бесконечного. 
Профессор СПбДА В. Н. Карпов оценивал способность человеческой души к сознанию еще более высоко, чем Голубинский [10, с. 272]. В отличие от Голубинского, полагавшего сознание как данность внутренних состояний души лишь первой ступенью познания душой собственного бессмертия, Карпов смотрел на сознание как на безусловное и самодостаточное начало умозрительной психологии. «Сознание в природе человеческого духа есть факт, свидетельствующий о самом себе чрез самого себя; оно есть единственная непосредственность или единственное непосредственное явление, для познания которого не требуется ничего другого, кроме его самого, тогда как само оно безусловно требуется для познания всего другого. Сознание есть свет, рассеивающий таинственный мрак, которым облечено нравственное существо человека...» [3, с. 195].

Именно в области сознания следовало с точки зрения многих представителей духовно-академической мысли искать обоснования бессмертия души. Причем в духе времени их рассуждения часто были выдержаны в рационально-логическом стиле, т. е. аргументы в пользу бессмертия души предписывалось искать не столько в непосредственном видении душой своего богоподобия, сколько в области разума. Хорошим примером академических попыток рационального обоснования бессмертия души может служить соответствующая глава лекций по метафизике СПбДА. Показательна в данном труде не только философская формулировка православного положения о бессмертии души: «Дух человеческий бессмертен, т. к. он будет продолжать свое бытие бесконечно и точно таким, каков по своей сущности в настоящем состоянии», но и четко сформулированные задачи философских интерпретаторов этой проблемы: «Задача философов состоит в том, чтобы прояснить, возможно ли и в какой степени возможно удовлетворительно ответить собственным разумом на вопрос о бессмертии души» ${ }^{1}$.

Поскольку положение - тезис о бессмертии конечного духа, т. е. человеческой души, - которое предстояло доказывать, было сформулировано авторами еще в начале главы (здесь, как и рациональных доказательствах бытия Бога, присутствует тот же логический прием, вскрытый еще Кантом: тезис, который предстоит доказывать, содержится уже в посылках), рассуждения авторов рукописи представляют собой не столько доказательство этого положения, сколько подбор историко-философского и богословского материала в его пользу, осуществляемый, впрочем, с характерной для всей духовно-академической мысли обстоятельностью.

Все доказательства бессмертия души подразделялись авторами лекций на три группы: онтологические - «идут от самого понятия о человеческом духе», нравственные - «идут от цели и закона человеческой воли», богословские - «идут от познания Бога». К онтологическим доказательствам авторы отнесли основную историко-философскую аргументацию, так или иначе обосновывающую неуничтожимость духа. С их точки зрения, даже материалисты не отрицают вечность духа, поскольку понимают духовное как проявление неуничтожимой материи. Установки материализма, естественно, не могли найти поддержку у академических мыслителей, но и не все идеалистические рассуждения относительно бессмертия духа получали их одобрение. Так, аргументация «идеалистического пан-

${ }^{1}$ Метафизика. Лекции, читанные в СПбДА. Сер ХІХ в. // Собрание редких книг МДА. ОР РГБ. 173 / IV. № 203. С. 72. 
И. В. Цвык. Проблема сущности души и ее бессмертия в русской духовно-академической традиции философии XIX в.

теизма», который «...смотрит на человеческий дух только как на проявление абсолютной деятельности, которая в своем процессе развития в самосознание, в одухотворение действительно на некоторых точках сего развития сделалась сознательною - духом», не кажется авторам рукописи убедительной. Более приемлемой авторы рукописи считали аргументацию дуализма: человеческий дух есть абсолютно простая субстанция, следовательно, он не может разрушиться путем разделения на элементы. Таким образом, остается две возможности уничтожения: либо в результате действия на него другого существа (это невозможно, так как если он должен уничтожиться действием на него другого существа, то он должен оставаться существующим во всем продолжении процесса уничтожения до конца), либо в результате постепенного истощения сил (что невозможно, так как дух есть реальность, следовательно, сила) ${ }^{1}$.

В разделе нравственных доказательств бессмертия души рассматривается в основном аргументация Канта. В полном соответствии с общими задачами философского истолкования религиозного сознания и обеспечения его обоснования с помощью новейших философских категорий и систем авторы рукописи анализировали проблему бессмертия души как постулат практического разума, используя положение Канта о бессмертии души как условии осуществления нравственного идеала. Закон практического разума есть идеал как цель для человека, образ деятельности, совершенно чуждый всякого эгоизма. Этот человеческий идеал может осуществиться только приблизительно, в бесконечном времени. Если требования практического разума не могут противоречить сущности человеческого духа, то дух должен существовать бесконечно и быть лицом, так как только при этом условии возможно осуществление нравственного идеала. Однако, соглашаясь с кантовскими рассуждениями, академические авторы все же стремились изменить содержание кантовской аргументации ссылкой на божественный источник нравственного закона. Анализируя традиционные богословские доказательства бессмертия души, авторы лекций отмечали, что эти доказательства, как правило, исходят из отдельно рассматриваемых свойств Божиих - всемогущества, премудрости, благости и правды. Однако при этом авторы решительно выступали против утверждения о невозможности постигнуть существо проблемы бессмертия духа посредством разума. Характерное для духовно-академической мысли рационалистического направления признание возможности рационального Богопознания закономерно привело и к признанию возможности и необходимости познания бессмертия души «из чисто разумного сознания». Причем познание Абсолютного, утверждение возможности которого явилось специфической чертой духовно-академической гносеологии XIX в., в свою очередь, выступало методологической основой для самопознания душой своего бессмертия. Так проблематика бессмертия души в духовно-академической философии заняла свое место в онтологических построениях академистов.

В конечном счете все попытки философского обоснования бессмертия души сводятся к утверждению в качестве основного аргумента ее божественного происхождения. Авторы лекций признают возможным «чисто умозрительное» познание бессмертия души, поскольку оно «основывается на том непосредственном сознании,

\footnotetext{
${ }^{1}$ Метафизика. Лекции, читанные в СПбДА. Сер ХІХ в. // Собрание редких книг МДА. ОР РГБ. 173 / IV. № 203. С. 77.
} 
что Бог есть основание бессмертия Духа». Итогом теоретических рассуждений авторов рукописи по поводу проблемы бессмертия души, таким образом, становится своеобразный логический круг: с одной стороны, бессмертие души обосновывается, главным образом, ее божественным происхождением; с другой - само наличие в человеке отличной от его телесности, духовной, бессмертной субстанции объявляется еще одним доказательством бытия Бога и залогом возможности богопознания.

На основании анализа духовно-академической аргументации можно сделать вывод о том, что строго логичного, рационального обоснования бессмертия души, как и бытия Бога, у академических авторов не получилось. Как и при попытке философской интерпретации Божественного бытия через традиционные доказательства бытия Бога, пытаясь обосновать бессмертие души, представители духовноакадемической мысли были вынуждены обратиться к богословской аргументации, для того чтобы не выйти за пределы православного учения. Тем не менее постановка вопроса о возможности философской интерпретации бессмертия души в рамках православной умозрительной, рациональной психологии, православная интерпретация осмысления этой проблемы западноевропейской философской мыслью свидетельствуют о том, что эти попытки академических профессоров не были абсолютно бесплодными в теоретическом отношении.

Подводя итог вышесказанному, следует отметить, что проблемы души и ее бессмертия в духовно-академической традиции обсуждались в русле двух разнонаправленных тенденций: в духе психологического идеализма, в большей степени свойственного Киевской и Казанской духовным академиям, и в соответствии с общими установками «верующего разума» Московской и Санкт-Петербургской академий. Причем вследствие характерного для духовно-академического философствования $\mathrm{XIX}$ в. стремления к теоретической и рационалистической интерпретации религиозного сознания в духе новейших западноевропейских философских идей, больший удельный вес занимала вторая тенденция, призванная представить логикорационалистическое обоснование бессмертия души и ее божественного происхождения. Однако эта линия академической мысли оказалась тупиковой: логикорационалистическое обоснование бессмертия души, опирающееся на доказательства бытия Бога, оказалось столь же слабым в теоретическом отношении и логически непоследовательным, как и сами доказательства. Именно поэтому тенденция логического обоснования бессмертия души практически не имела своего продолжения в академической мысли начала XX в. В этот период на первый план в духовноакадемическом философствовании выходит «религиозная антропология в пределах сознания».

\section{Литература}

1. Гаврюшин Н. К. Самопознание как таинство // Предисловие к кн. Русская религиозная антропология. Т. І: Антология. М.: Московский философский фонд, Московская духовная академия, 1997. $528 \mathrm{c}$.

2. Голубинский Ф. А. Умозрительная психология. М., 1871. 62 c.

3. Карпов В. Н. Вступительная лекция в психологию // Христианское чтение. 1868. Ч. I. C. $190-208$.

4. Коцюба В. И. Духовно-академическая философия первой половины XIX века и ее оценка в трудах отечественных и зарубежных мыслителей и исследователей. М.: Академика, 2014. $671 \mathrm{c}$. 
И. В. Цвык. Проблема сущности души и ее бессмертия в русской духовно-академической традиции философии XIX в.

5. Куценко Н. А. Духовно-академическая философия в России первой половины XIX века: киевская и петербургская школы. М., ИФ РАН, 2005. 144 с.

6. Пишун С. В. Теистическая концепция религии и познания Сверхсущего В. Д. Кудрявцева-Платонова // Социальные и гуманитарные науки на Дальнем Востоке. 2017. № 3. С. 123-127.

7. Феофан (Авсенев П. С.). Из записок по психологии // Сборник из лекций бывших профессоров Киевской духовной академии. Киев [б. и.], 1869. С. 2-88.

8. Цвык И. В. Духовно-академическая философия ХІХ в. М.: Изд-во РУДН, 2002. $333 \mathrm{c}$.

9. Шарова М. А. Философия и теистическая психология П. С. Авсенева (анализ работы «Из записок по психологии») // Исторические, философские, политические и юридические науки, культурология и искусствоведение. Вопросы теории и практики. 2015. № 2-2(52). С. 209-213.

10. Шевцов А. В. Логико-гносеологическое направление философии в СанктПетербургской духовной академии // Христианское чтение. 2017. № 1. С. 263-284.

\title{
PROBLEM OF THE ESSENCE AND IMMORTALITY OF THE SOUL IN THE RUSSIAN SPIRITUAL AND ACADEMIC PHILOSOPHY OF THE $19^{\text {th }}$ CENTURY
}

\author{
Irina $V$. Tsvyk \\ Dr. Sci. (Philos.), Prof. of Philosophy Department, \\ Moscow Aviation Institute (National Research University), \\ 4 Volokolamskoye Highway, Moscow 125993, Russia \\ Peoples' Friendship University of Russia, \\ 6 Miklukho-Maklaya St., Moscow 117198, Russia \\ E-mail: tsvykirina@mail.ru
}

The article studies the doctrine of the soul, its origin and immortality, formulated in the framework of the Russian spiritual and academic philosophy of the $19^{\text {th }}$ century. We have considered the logical-rationalistic and ethical-anthropological trends in spiritual and academic interpretations of the problem of essence and origin of the soul. It is noted that the problems of the soul and its immortality in the spiritual and academic tradition were discussed in the context of two multidirectional tendencies: in keeping with psychological idealism, more typical of Kiev and Kazan Theological Academies, and in accordance with the general attitudes of "the believing mind" of Moscow and St. Petersburg Academies. Based on the analysis of the spiritual and academic argumentation of the immortality of the soul, we have concluded that there was no strictly logical, rational justification for the immortality of the soul, like for the existence of God, in spiritual and academic philosophy. Trying to substantiate the immortality of the soul, the representatives of spiritual and academic thought were forced to turn to theological argumentation in order not to go beyond the limits of Orthodox doctrine. Nevertheless, posing the question of the possibility of philosophical interpretation of the immortality of the soul within the framework of Orthodox speculative, rational psychology, as well as an Orthodox interpretation of understanding this problem by Western European philosophical thought testifies that these attempts of the academic professors were not completely fruitless in theoretical terms and played the significant role in the development of epistemological problems of the Russian philosophy of the late $19^{\text {th }}$ - early $20^{\text {th }}$ centuries.

Keywords: spiritual and academic philosophy; soul; cognition; religious consciousness; immortality of the soul; speculative psychology; rational knowledge of God; P. S. Avsenev; F. E. Golubinsky; V. N. Karpov. 